\section{Hiding in plain sight: supporting primary care to find familial hypercholesterolaemia and save lives}

\author{
Nadeem Qureshi (10), ${ }^{1}$ Riyaz S Patel (1) 2,3
}

Familial hypercholesterolaemia $(\mathrm{FH})$ is a relatively common genetic disorder, with affected individuals exhibiting a lifelong elevation of plasma low-density lipoprotein (LDL) cholesterol and a marked tendency to premature atherosclerosis and early-onset cardiovascular disease (CVD). However, unlike most genetic disorders, FH is wholly treatable, especially following the widespread availability of potent lipidlowering agents such as statins. Indeed, early and sustained therapy to lower LDL cholesterol can normalise this risk and prevent premature CVD.

With such enormous potential to prevent premature CVD, it is surprising then that only $7 \%$ of patients with $\mathrm{FH}$ are believed to have been identified in the UK. The picture is similar in many countries. In England, the NHS Long Term Plan has recently prioritised finding more of these undiagnosed patients and offering them treatment. ${ }^{1}$ Yet, the task of finding these people and their families, many of whom may be otherwise well, is enormously challenging for a multitude of reasons, one of which is lack of awareness of the diagnosis. The situation could be improved by supporting primary care to identify those with high cholesterol levels and clinical features of $\mathrm{FH}$, offering them an evaluation to confirm diagnosis before moving on to find their relatives, half of whom may carry the same mutation.

\section{IDENTIFYING FH IN PRIMARY CARE USING CURRENT INFRASTRUCTURE}

Brett et al in their study have shown that by simply using the current infrastructure of general practice, those affected by this condition can be successfully identified and treated. ${ }^{2}$ The primary care electronic health record (EHR) is of course the key game changer, enabling swift

\footnotetext{
${ }^{1}$ NIHR School of Primary Care Research, University of Nottingham, Nottingham, UK

${ }^{2}$ Institute of Cardiovascular Sciences, University College London, London, UK

${ }^{3}$ The Barts Heart Centre, St Bartholomew's Hospital, London, UK

Correspondence to Professor Nadeem Qureshi, NIHR School of Primary Care Research, University of Nottingham, Nottingham NG7 2UH, UK;

nadeem.qureshi@nottingham.ac.uk
}

identification of people in whom the diagnosis may be likely. Several variations to the approach of using EHR to identify FH cases have been described as shown in figure 1. Options include systematically searching the records using established diagnostic criteria, such as Dutch Lipid Clinic Network (DLCN) criteria as used in the TARB-Ex tool ${ }^{2}$ or novel case-finding tools, such as FAMCAT. $^{3}$ In parallel, electronic searches could create patientspecific computer reminders which alert the general practitioner (GP) opportunistically when a patient at increased risk of FH is seen. ${ }^{4}$

Using EHR searches to identify patients at increased risk is a well-established case finding approach in primary care; for example, atrial fibrillation search tools have been used to identify stroke risk in affected patients leading to an increase in rates of anticoagulation. ${ }^{5}$ Furthermore, with the NHS health checks, more people have had their cholesterol profiles measured, along with discussions about cardiovascular risk in primary care, meaning this approach is well suited for FH identification. ${ }^{6}$ Clearly, the infrastructure is there to identify these individuals, but there are still important hurdles to overcome.

\section{CHALLENGES FOR PRIMARY CARE FH IDENTIFICATION}

First, the EHR searches are only as good as the data the records have captured. Cholesterol levels on their own are not sufficient to find patients with $\mathrm{FH}$, and other information, such as a family history of premature CVD or hypercholesterolaemia and physical signs, particularly tendon xanthoma, is needed to estimate the probability of FH. Currently, these are often poorly recorded or omitted altogether. Until this is resolved, EHR searches at best will only find people with a modestly high possibility of $\mathrm{FH}$, thus necessitating a second step of formal clinical assessment of this targeted group.

Herein lies the next challenge as demonstrated by Brett et al, the question of motivation. Patients need to be contacted and assessed when they are not seeking healthcare, for a condition that has no symptoms or immediate perceived threat attached to it and a topic around which there is an emotive response in the media. Unsurprisingly, as with other primary care FH studies, Brett et al found a significant proportion of patients failed to attend for these assessments. ${ }^{2}$ Cholesterol, unlike blood pressure, has failed to trigger a sense of urgency or importance, which affects not only the public's behaviour but also that of clinicians. Increasing education among clinicians, as well as raising public awareness of the condition and the risk it entails, therefore has to go hand in hand with any case finding approach. In that regard, Brett et al show some promise in that educating GPs about FH seemed to improve management.

\section{WHERE NEXT FOR CASE FINDING IN PRIMARY CARE?}

Assuming the quality of records remains as they are for the foreseeable future, while public and clinician engagement and education may be improved, how can primary care better identify patients with FH? The key next step is a clinical assessment of this targeted at-risk population, but who would deliver this in a busy general practice? Unlike the approach from Brett et al, it is unlikely that outside rural Australia, most GPs would have time to invite and assess hundreds of patients. An alternative is to involve other healthcare practitioners in primary care, such as healthcare assistants, practice-based pharmacists and nurses, to take on the task of evaluating patients for FH. Clinical nurse specialists for $\mathrm{FH}$ are highly skilled at this clinical assessment, yet they are few and far between and employing them for this role would be expensive, but they could take on a more advisory role to support the relevant healthcare practitioners in each practice, perhaps with virtual reviews of more challenging cases. Thereafter, once cases with higher likelihood are identified, they could be referred for specialist evaluation, genetic testing and management in secondary care. This type of model with close primary and secondary care interaction has been successfully deployed for conditions such as atrial fibrillation. ${ }^{5}$ Whatever pathway is developed needs to consider the target population from the outset to prevent perpetuating inequalities.

Given the central role of genetics in making a diagnosis of $\mathrm{FH}$ and permitting cascade testing, a further innovation thrown into the mix could be for GPs to offer genetic testing early on, once patients 


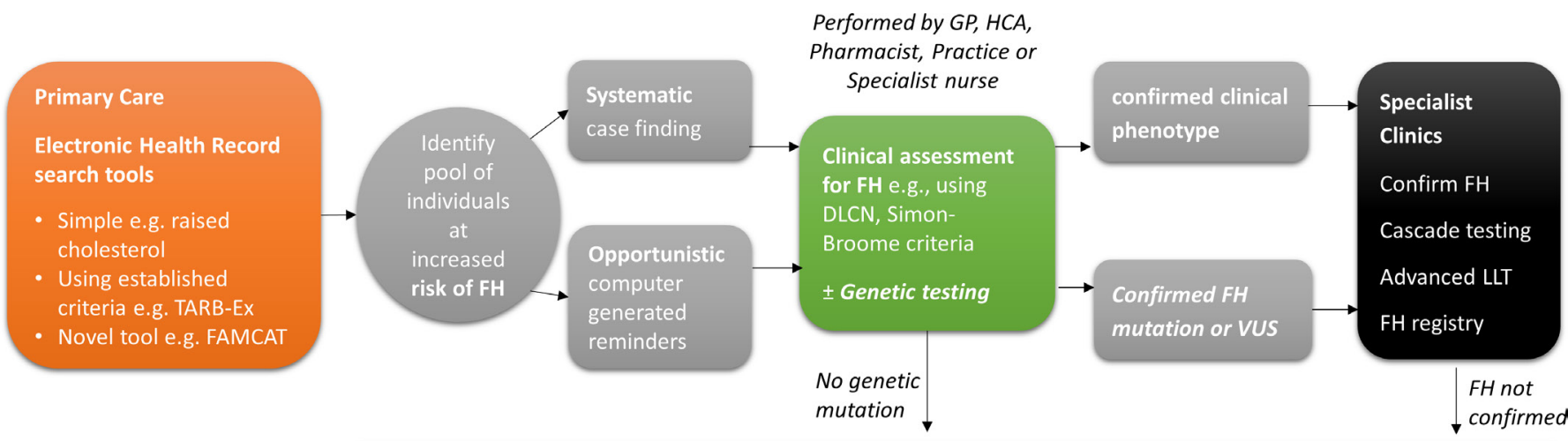

CVD Risk management in primary care for all, including those with polygenic hypercholesteroleamia

Figure 1 Pathway to identification of FH from primary care. CVD, cardiovascular disease; DLCN, Dutch Lipid Clinic Network; FH, familial hypercholesterolaemia; GP, general practitioner; HCA, healthcare assistant; LLT, lipid-lowering treatment; VUS, variant of unknown significance.

meeting a certain diagnostic threshold are identified (eg, DLCN score over 5). However, with the introduction of more advanced next-generation sequencing, the interpretation of the genetic results is even more challenging, especially when variants that are not clearly disease causing (variants of unknown significance (VUSs)) are identified. These VUSs still need referral for further investigation, but the primary care professional would need to explain the uncertainty and offer some degree of genetic counselling. Furthermore, where a genetic mutation is not identified $(\sim 20 \%$ to $30 \%$ of $\mathrm{FH}$ cases) and instead minor variations in several genes are found, also known as polygenic hypercholesterolaemia, GPs would need to know how to explain these results and manage the clinical phenotype.

The key role of genetic testing, of course, is to find a mutation that can be used for cascade testing and to find relatives who may or may not have very high levels of cholesterol. Brett et al have also suggested that cascade testing may be offered through primary care, noting each FH confirmed individual may identify up to five other relatives that may benefit from $\mathrm{FH}$ assessment. Caring for families is the foundation of general practice, and this approach may still hold in rural areas where several generations live locally. However, with population mobility, this is less likely to be the case especially in more urban areas. Under these circumstances, general practice-based cascade testing is impractical, other than GPs possibly supporting indirect cascade testing. The latter involves relatives at risk of $\mathrm{FH}$, contacted through the affected individual rather than directly by the specialist. An alternative is to have community-based nurse specialists offering cascade testing across groups of practices.
Whether genetic testing is offered by GPs or in lipid clinics, ultimately a key requirement for successfully finding $\mathrm{FH}$ cases at scale is for centralised and national registries of patients with $\mathrm{FH}$ to monitor the success of case finding efforts but also to enable cascade testing nationally through pedigree-based systems, such as PASS software. Such a national database has been setup in Australia, but this is lacking in many nations, including the UK. However, efforts are ongoing to develop this.

\section{CONCLUSION}

Ultimately, successfully identifying the thousands of people with FH in the UK and abroad will require a system-wide approach from opportunistic identification at routine health encounters, systematic case finding in primary care, screening people at the time of a premature CVD event to child-parent screening and cascade testing. Brett et al have shown that primary care has the infrastructure and ability to identify many individuals with possible $\mathrm{FH}$ in their practices, using searches of general practice EHRs as a key starting point. Our challenge is to organise our primary healthcare teams and pathways to convert those in whom we have a high index of suspicion to a firm diagnosis of $\mathrm{FH}$ and to initiate appropriate management. ${ }^{8}$ It is at this point of clinical assessment that primary care needs the most support from specialists, in particular, community-based FH nurses. Thus, although many patients with $\mathrm{FH}$ may be hidden in primary care, only a team effort can successfully uncover them and in the process save lives.

Contributors NQ wrote the first draft and RSP redrafted the manuscript.
Funding The authors have not declared a specific grant for this research from any funding agency in the public, commercial or not-for-profit sectors.

Competing interests NQ has received speaker fees from Amgen. RSP has received speaker fees and honoraria from companies manufacturing lipid-lowering agents, including Amgen, Sanofi and Novartis.

Patient and public involvement Patients and/or the public were not involved in the design, conduct, reporting or dissemination plans of this research.

Patient consent for publication Not required.

Provenance and peer review Commissioned; externally peer reviewed.

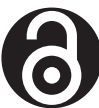

\section{OPEN ACCESS}

Open access This is an open access article distributed in accordance with the Creative Commons Attribution Non Commercial (CC BY-NC 4.0) license, which permits others to distribute, remix, adapt, build upon this work non-commercially, and license their derivative works on different terms, provided the original work is properly cited, appropriate credit is given, any changes made indicated, and the use is non-commercial. See: http://creativecommons.org/ licenses/by-nc/4.0/

(c) Author(s) (or their employer(s)) 2021. Re-use permitted under CC BY-NC. No commercial re-use. See rights and permissions. Published by BMJ.

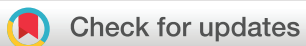

To cite Qureshi N, Patel RS. Heart 2021;107:1190-1192.

Published Online First 20 May 2021

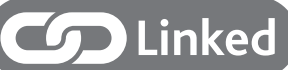

- http://dx.doi.org/10.1136/heartjnl-2020-318813

Heart 2021:107:1190-1192.

doi:10.1136/heartjnl-2021-319266

ORCID iDs

Nadeem Qureshi http://orcid.org/0000-0003-49090644

Riyaz S Patel http://orcid.org/0000-0003-4603-2393 


\section{REFERENCES}

1 The NHS long term plan; January 2019 (cardiovascular chapter: section 3.68). Available: https://www. longtermplan.nhs.uk/wp-content/uploads/2019/08/ nhs-long-term-plan-version-1.2.pdf [Accessed 22 Mar 2021].

2 Brett T, Chan DC, Radford J, et al. Improving detection and management of familial hypercholesterolaemia in Australian general practice. Heart 2021;106:1213-9.

3 Weng S, Kai J, Akyea R, et al. Detection of familial hypercholesterolaemia: external validation of the
FAMCAT clinical case-finding algorithm to identify patients in primary care. Lancet Public Health 2019;4:e256-64.

4 Qureshi N, Weng S, Tranter J, et al. Feasibility of improving identification of familial hypercholesterolaemia in general practice: intervention development study. BMJ Open 2016;6:e011734.

5 Chahal JK, Antoniou S, Earley M, et al. Preventing strokes in people with atrial fibrillation by improving ABC. BMJ Open Qual 2019;8:e000783.

6 Patel R, Barnard S, Thompson K, et al. Evaluation of the uptake and delivery of the NHS health check programme in England, using primary care data from 9.5 million people: a cross-sectional study. BMJ Open 2020;10:e042963.

7 Roberts MC, Mensah GA, Khoury MJ. Leveraging implementation science to address health disparities in genomic medicine: examples from the field. Ethn Dis 2019;29:187-92.

8 Watts GF, Sullivan DR, Hare DL, et al. Integrated guidance for enhancing the care of familial hypercholesterolaemia in Australia. Heart Lung Circ 2021;30:324-49. 